\title{
PENGEMBANGAN MEDIA PEMBELAJARAN BERBASIS ANDROID PADA MATA PELAJARAN PENGENALAN MICRODOFT WORD DI LPK SHEZA PONTIANAK
}

\author{
Danar Santoso $^{1)}$, Dochi Ramadhani ${ }^{2)}$ \\ ${ }^{1,2}$ Prodi Pendidikan Teknologi Informasi dan Komputer, IKIP PGRI Pontianak \\ Email : ${ }^{1}$ gravien21@gmail.com, ${ }^{2}$ emaildochi@gmail.com
}

\begin{abstract}
The purpose of the study was to find out how the development of Android-based learning media for the LPK training and course institutions SHEZA, to find out the feasibility of Android-based learning media for LPK training institutions and SHEZA courses. Learning media is designed using the Pascal programming language with the application of Embacadero Delphi XE 8. The Android platform was chosen because all LPK Sheza students use an Android smartphone, the microsoft word learning media developed is an Android-based learning media. because Android-based devices have been widely used in communities from various circles. So that the use of mobile devices or smartphones among users is optimal especially for learning. The hope, this study can facilitate educators or students in particular to increase the spirit of learning and achieve its goals in learning. The study was conducted at LPK SHEZA. The type of research used is $R \& D$ research. The research was conducted in two stages. The first stage for product development uses the ADDIE model and the second stage. Data collection techniques use measurement and direct communication. The data collection tool uses an interview guide and questionnaire. The results of the study are the development of Android-based learning media for LPK training institutions and SHEZA courses worthy of use.
\end{abstract}

Keywords: Development, Media, Android.

\section{INTISARI}

Tujuan penelitian adalah untuk mengetahui bagaimana pengembangan media pembelajaran berbasis Android untuk untuk LPK lembaga pelatihan dan kursus SHEZA, Mengetahui kelayakan media pembelajaran berbasis Android untuk LPK lembaga pelatihan dan kursus SHEZA. Media pembelajaran dirancang dengan menggunakan bahasa pemrograman pascal dengan aplikasi Embacadero Delphi XE 8. Platfrom android dipilih dikarenakan seluruh peserta didik LPK Sheza menggunakan smartphone android, Media pembelajaran microsoft word yang dikembangkan merupakan Media pembelajaran berbasis Android. dikarenakan perangkat berbasis android sudah banyak digunakan di masyarakat dari berbagai kalangan. Sehingga penggunaan perangkat mobile atau smartphone di kalangan pengguna optimal apalagi untuk pembelajaran. Harapannya, penelitian ini dapat memudahkan pendidik atau peserta didik khususnya untuk meningkatkan semangat belajar dan mencapai tujuannya dalam pembelajaran. Penelitian dilaksanakan di LPK SHEZA. Jenis penelitian yang digunakan adalah penelitian R\&D. Penelitian dilakukan dengan dua tahap. Tahap pertama untuk pengembangan produk menggunakan model ADDIE dan tahap kedua. Teknik pengumpulan data menggunakan pengukuran dan komunikasi langsung. Alat pengumpulan data menggunakan ppanduan wawancara dan angket. Hasil penelitian yaitu pengembangan media pembelajaran berbasis Android untuk untuk LPK lembaga pelatihan dan kursus SHEZA layak digunakan.

Kata kunci : Pengembangan, Media, Android.

\section{PENDAHULUAN}

IPTEK atau Ilmu pengetahuan dan teknologi dapat membantu manusia dalam mengerjakan suatu pekerjaan baik dari segi tenaga maupun waktunya. Dengan adanya perkembangan ilmu pengetahuan dan teknologi informasi telah menggeser pembelajaran yang menggunakan pembelajaran konvensional menjadi pembelajaran yang berbasis teknologi. Pendidikan merupakan salah satu penunjang keberhasilan suatu bangsa, sehingga pendidikan dapat diperlukan untuk pengembangkan potensi sumber daya manusia 
dalam Penguasaan kompetensi keahlian dalam kaitannya denga IPTEK. Dalam pendidikan pada dasarnya peserta didik dibekali dengan keahlian dibidangnya masing-masing sehingga peserta didik bisa mengembangkan potensi yang ada dalam diri peserta didik itu sendiri dan keberhasilan bisa tercapai dalam proses pembelajaran.

Media pembelajaran merupakan salah satu yang bisa digunakan peserta didik maupun didalam pendidikan formal, informal maupun non formal. Pendidikan menurut Undang-Undang nomor 20 tahun 2003 bahwa jalur pendidikan terdiri atas pendidikan formal merupakan pendidikan yang diselenggarakan di lingkungan sekolah, pendidikan jalur formal ini terdiri atas pendidikan dasar, pendidikan menengah dan pendidikan tinggi. Pendidikan informal merupakan salh satu pendidikan keluarga dan lingkungan terbentuk dari kegiatan belajar secara mandiri yang dilakukan secara sadar dan bertanggung jawab. Salah satunya adalah jalur pendidikan nonformal merupakan jalur pendidikan keluarga dan lingkungan berbentuk kegiatan belajar secara mandiri yang dilakukan secara sadar dan bertanggung jawab. Pendidikan nonformal berfungsi mengembangkan potensi peserta didik dengan penekanan pada penguasaan pengetahuan dan keterampilan fungsional serta pengembangan sikap dan kepribadian profesional. Satuan pendidikan nonformal terdiri atas lembaga kursus, kelompok belajar, lembaga pelatihan, pusat kegiatan belajar masyarakat, majelis taklim dan satuan pendidikan yang sejenis.

Dengan menggunakan media pembelajaran, proses pembelajaran dapat terbantu dikarenakan media pembalajaran membantu pemahaman siswa terhadap materi pembelajaran yang diberikan oleh pengajar.

Berdasarkan observasi dan penelitian yang telah dilaksanakan pada pendidikan nonformal dilembaga pelatihan dan kursus SHEZA, bahwa lembaga pelatihan dan kursus SHEZA membutuhkan media pembelajaran berbasis android, dikarenakan perangkat berbasis android sudah banyak digunakan di masyarakat dari berbagai kalangan. Sehingga penggunaan perangkat mobile atau smartphone di kalangan pengguna optimal untuk pembelajaran. Berdasarkan permasalahan sebelumnya, peneliti bermaksud menganalisis kebutuhan media pembelajaran yang dapat melatih kemandirian peserta didik dan mempermudah peserta didik dalam memahami materi pelajaran, dari hasil penelitian sebelumnya juga telah dihasilkan sebuah perancangan desain antarmuka dan sistem dari aplikasi media pembelajaran berbasis android yang akan dilanjutkan dengan pembuatan aplikasi berdasarkan rancangan yang telah dilakukan. Media pembelajaran yang dikembangkan adalah Media pembelajaran berbasis Android.

Media pembelajaran yang dikembangkan adalah Media pembelajaran berbasis Android. dikarenakan perangkat berbasis android sudah banyak digunakan di masyarakat dari berbagai kalangan. Sehingga penggunaan perangkat mobile atau smartphone di kalangan pengguna optimal apalagi untuk pembelajaran. Harapannya, penelitian ini dapat memudahkan pendidik atau peserta didik khususnya untuk meningkatkan semangat belajar dan mencapai tujuannya dalam pembelajaran.

\section{PENDEKATAN PEMECAHAN \\ MASALAH}

Metode penelitian yang digunakan adalah metode penelitian dan pengembangan atau Research and Development. Penelitian pengembangan merupakan suatu kajian sistematik terhadap desain, pengembangan dan evaluasi suatu program, proses dan produk yang harus memenuhi kriteria kepraktisan, validitas dan efektivitas.

Dalam penelitian ini produk media pembelajaran dibuat dengan empat tahapan yaitu studying research, developing product, field testing, dan revising. Dalam studying research atau studi awal penelitian ditemukan bahwa terdapat permasalahan dalam proses pembelajaran antara lain :

1. Materi bersifat offline

2. Kecendrungan peserta didik untuk lebih lama memerhatikan smartphone

3. Tidak adanya media pembelajaran mobile

4. Belum memiliki media evaluasi yang membantu

Materi yang bersifat offline membuat perserta didik pasif untuk belajarn dan mendalami microsoft word sehingga hasil evaluasi dalam pembelajaran cenederung kurang dan peserta didik kurang mendalami materi.

Kecendrungan peserta didik untuk bermain smartphone dibanding belajar membuat efektivitas pembelajaran di kelas terganggu dan proses pembelajaran juga tidak berjalan dengan baik sehingga pemahaman materi oleh peserta didik juga kurang baik.

Smartphone sangat populer dikalangan semua orang pada saat ini. Semua kebutuhan dan telekomunikasi mengandalkan perangkat pintar tersebut. Semua kalangan masyarakat dari kecil sampai dewasa memiliki perangkat tersebut, 
alangkah baiknya penggunaan perangkat pintar tersebut dapat dimaksimalkan sebagai media pembelajaran yang akan membantu pemahaman peserta didik akan materi yang sedang berjalan.

Belum tersedianya media evaluasi membuat pelaksanaan evaluasi berjalan secara klasikal dan menggunakan kertas sehingga membutuhkan waktu dalam pengkoreksian hasil jawaban yang telah dilakukan oleh peserta didik. Dengan adanya media pembelajaran berbasis android ini, evaluasi akan berjalan secara realtime dan otomatis sehingga peserta didik akan mendapatkan hasil nilai dengan cepat dan dapat mengetahui dan mempelajari jawaban yang benar dari masingmasing soal.

Pada tahapan developing product atau pengembangan produk peneliti fokus untuk membuat algoritma serta flowchart yang digunakan untuk pengembangan media pembelajaran untuk LPK Sheza. Peneliti menggunakan borland Embacadero Delphi 8.1 dan bahasa pemrograman pascal. Produk yang dihasilkan adalah berupa instalasi android atau apk yang akan diinstal secara offline ke masing-masing smartphone pserta didik. Dalam tahapan ini juga dilibatkan beberapa pengajar dari LPK Sheza untuk berpartisipasi memberikan masukkan dalam pengembangan media pembelajaran. Dengan begitu hasil pengembangan produk dapat bermanfaat bagi LPK Sheza.

Pada tahapan field testing aplikasi yang dihasilkan akan digunakan kepada seluruh peserta didik yang ada di LPK Sheza. Hasil dari filed testing ini akan berupa masukkan atau perbaikan desain dalam pengembangan selnjutnya. Sehingga dihasilkan produk aplikasi yang lebih baik lagi.

Pada tahapan revising produk yang telah diberikan masukkan pada tahapan sebelumnya atau filed testing akan mengalami revisi produk sesuai dengan masukkan. Hasil akhir dari proses ini adalah produk akhir yang telah disempurnakan dan siap untuk digunakan pada proses pembelajaran di LPK selanjutnya.

\section{HASIL DAN PEMBAHASAN}

Hasil dan pembahasan dapat digabung atau dipisah. Dapat digabung hanya jika permasalahannya sederhana. Jika dipisah format lebih rapi dan jelas mana hasil penelitian sendiri dan mana hasil penelitian orang lain. Argumentasi peneltian dapat dikembangkan lebih baik, jika dipisah.

Media Pembelajaran dikembangkan dengan menggunakan aplikasi Embacadero Delphi 8.1 dengan bahasa pemrograman pascal yang kemudian akan diubah ke dalam bahasa HTML 5.
Bahasa pemrograman menggunakan bahasa pascal karena bahasa pemrograman yang paling sederhana dan mudah untuk diterapkan, kemudian diubah dalam bentuk HTML 5 agar bisa di konversi kedalam aplikasi android. HTML 5 digunakan karena bahasa yang diguankan hampir mirip dengan bahasa java yang digunakan pada android. Aplikasi yang akan dihasilkan akan berupa instalasi android atau apk yang akan di instal manual di dalam ponsel android. Media pembelajaan yang telah dirancang dapat dijelaskan sebagai berikut :

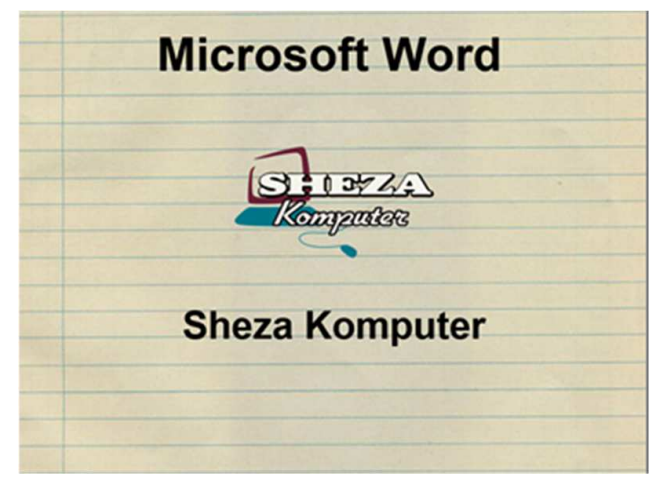

Gambar 1. Halaman Awal Aplikasi

Pada halaman ini ditampilkan splash screen dari aplikasi dan pengenalan materi yang akan diajarkan pada media pembelajaran.

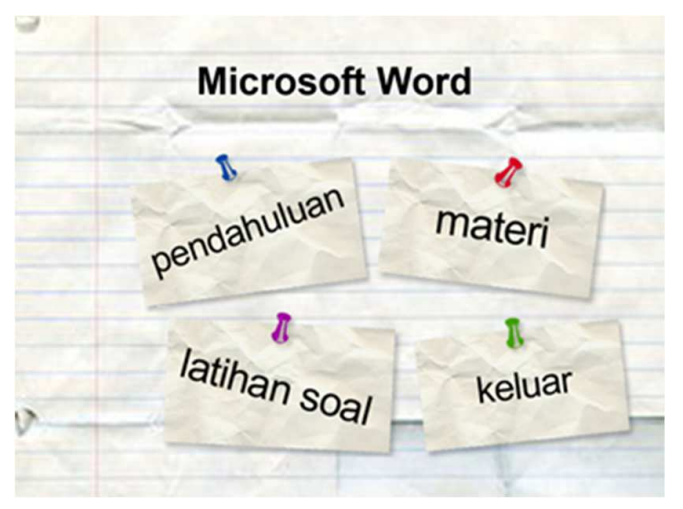

Gambar 2. Menu Awal Aplikasi

Pada menu aplikasi terdapat menu pilihan yaitu pemdahuluan, materi, latihan soal dan keluar. Pada menu ini peserta didik dapat memilih bagian dari materi yang akan dipelajari sehingga memudahkan peserta didik dalam mempelajari materi. 


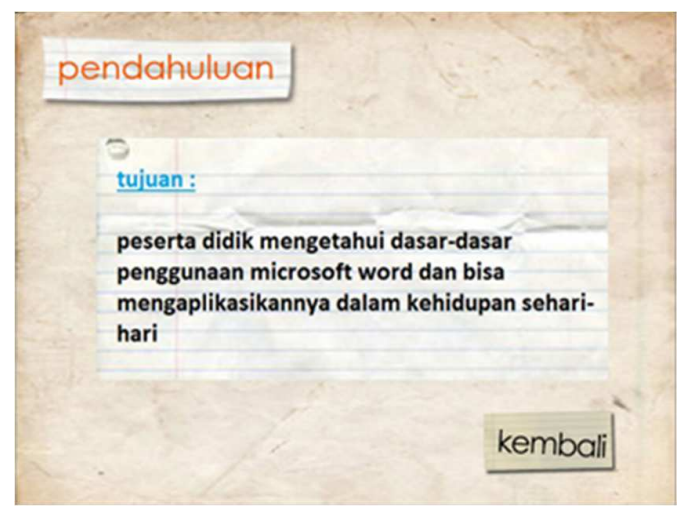

Gambar 3. Menu Pendahuluan

Pada menu pendahuluan aplkasi berisi tujuan pembuatan aplikasi. Pada menu ini peserta didik dapat mengetahui tujuan materi pembelajaran yang tersedia.

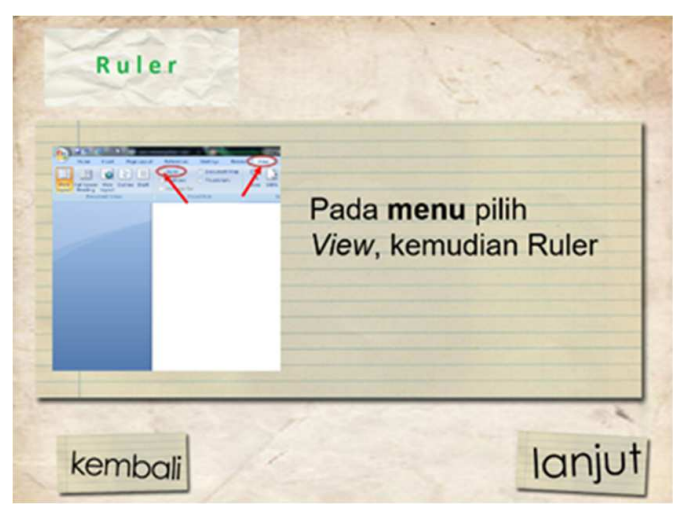

Gambar 4. Halaman Materi Aplikasi

Pada halaman materi aplikasi berisi tentang materi yang berkaitan dengan pembelajaran yang ada pada LPK Sheza. Materi yang disediakan adalah microsoft word yang dimana terbagi kedalam beberapa bab.

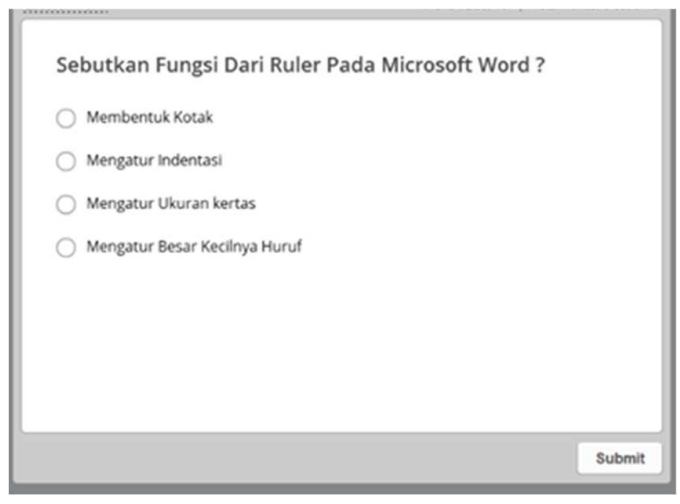

Gambar 5 Halaman Evaluasi Aplikasi

Pada menu evaluasi terdapat 10 soal evaluasi yang berkaitan tentang pembelajaran yang telah diajarkan dan pada menu ini aplikasi dapat menghitung otomatis berapa nilai yang diperoleh oleh peserta didik.

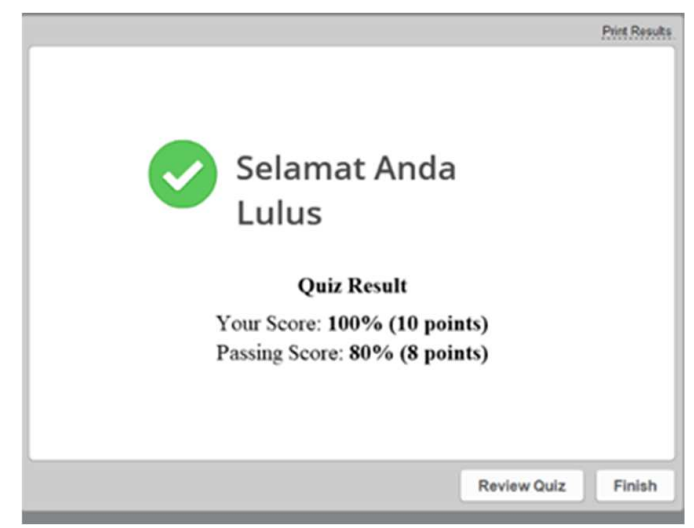

\section{Gambar 6 Halaman Hitung Nilai Evaluasi}

Pada menu ini peserta didik dapat mengetahui hasil nilai perolehan dari evaluasi yang tersedia pada aplikasi. Di halaman menu ini juga peserta didik juga dapat mengetahui jawaban yang benar dari beberapa soal yang salah dijawab sehingga dapat dipelajari untuk kedepannya.

\section{KESIMPULAN}

Berdasarkan data dan pembahasan yang diperoleh pada penelitian ini dapat disimpulkan sebagai berikut:

1. Dihasilkan sebuah media pembelajaran berbasis android yang dapat digunakan sebagai alternatif pembelajaran dimanapun dan kapan saja dengan menggunakan smartphone yang dimiliki masing-masing peserta didik.

2. Media pembelajaran yang dihasilkan hanya ditujukan untuk android versi 5.0 keatas. Hal ini dikarenakan setelah mewawancara peserta didik dan pengajar yang ada ditemukan bahwa smartphone yang digunakan adalah smartphone android dengan versi 5.0 keatas.

3. Untuk penggunaan dikomputer peserta didik masih menggunakan emulator android agar bisa memanfaatkan media pembelajaran yang tekah dirancang. Hanya saja untuk emulator diharapkan emulator yang telah menggunakan adnroid versi 5.0 keatas agar aplikasi bisa terpasang dan berjalan dengan baik pada komputer.

4. Dalam media pembelajaran yang dirancang terdapat beberapa menu yang dapat diakses yaitu: 
a. Pendahuluan yang berisi tentang tujuan pembelajaran

b. Materi yaitu berisi materi pembalajaran yang terdiri dari beberapa sub bab yang dapat diakses

c. Evaluasi berisi soal-soal evaluasi beserta hasil penilaian yang dapat diakses ketika soal selesai. Pada menu ini juag terdapat pembahasan yang memungkinkan peserta didik untuk belajar dari kesalahan yang telah dilakukan

d. Keluar pada tombol ini berguna untuk mematikan aplikasi apabila telah digunakan

5. Pengembangan media pembelajaran berbasis android di LPK Sheza Pontianak akan memberikan hasil keluaran berupa aplikasi android. Pengembangan media pembelajaran dilakukan melalui 4 tahap pengembangan yaitu a. analisis; b. perencanaan; c. pengembangan; dan d. implementasi.

a. Analisis dilakukan dengan menganalisis terhadap data-data observasi lapangan, hasilnya adalah sebagai berikut: 1) Pengajar belum memanfaatkan media pembelajaran berbasis android pada proses pembelajaran; 2) Peserta didik dalam proses pembelajaran cenderung tidak mengulangi pembelajaran pada saat ada waktu luang; 3) Pengajar hanya menggunakan sumber belajar buku teks dan powerpoint saat di LPK sebagai media pembelajaran; 4) tidak tersedianya media evaluasi yang dapat memberikan evaluasi secara otomatis dan cepat serta terdapat pembahasan yang memungkinkan peserta didik untuk belajar dari kesalah jawaban yang telah dilakukan. Sehingga proses pembelajaran dapat dilakukan dengan baik.

b. Perencanaan dilakukan dengan merancang flowchart dan desain antarmuka yang disesuaikan dengan keinginan pengajar sehingga bisa dihasilkan aplikasi yang sesuai.

c. Pengembangan dilakukan dengan cara pengembangan aplikasi menurut flowchart dan desain antarmuka yang disesuaikan dengan kemauan dari para pengajar. Didalam pengembangan aplikasi peneliti mengunakan embacadero borland delphin 8.1 XE dengan bahasa pemrograman pascal dan kemudian setelah selesai, aplikasi dikonversi ke bentuk HTML 5 dengan menggunakan aplikasi ispring, setelah konversi selesai aplikasi dikonversi kembali ke bentuk apk dengan menggunakan aplikasi phone gap sehingga diperoleh prototype awal aplikasi yang siap diguanakan di lapangan.

d. Implementasi dilakukan dengan mengimplementasikan dan menginstall aplikasi yang telah dibuat ke smartphone peserta didik. Sehingga bisa didapat umpan balik dari peserta didik sehingga aplikasi bisa direvisi menjadi lebih baik lagi. Didalam implementasi melibatkan seluruh peserta didik dan seluruh pengajar yang ada di LPK Sheza sehingga bisa diperoleh umpan yang baik dari kedua belah pihak yang bisa dijadikan bahan pertimbangan dalam revisi penelitian.

\section{DAFTAR PUSTAKA}

[1] Arief S. Sadiman, dkk. Media Pendidikan: Pengertian, Pengembangan, dan Pemanfaatannya. Jakarta: Rajawali. 2014.

[2] Ghufron, A. Pendekatan Penelitian dan Pengembangan $(R \& D)$ di Bidang Pendidikan dan Pembelajaran. Handout. Fakultas Ilmu Pendidikan UNY. 2011.

[3] Hannafin, M. J \& Peek, K. L. The design, development, and evaluation of instructional software. New York: Macmillan Publishing Company. 1988.

[4] I Gde Wawan Sudatha \& I Made Tegeh. Desain Multimedia Pembelajaran. Buku ajar. UNDIKSHA. 2009.

[5] Jamal Ma'mur Asmani. Teknologi Informasi dan Komunikasi dalam Dunia Pendidikan. Yogyakarta: Diva Press. 2011.

[6] Nasution, S. Teknologi Pendidikan. Jakarta: Bumi Aksara. 2012.

[7] Rudi Susilana, dkk. Ilmu dan Aplikasi Pendidikan. Bandung: PT Imperal Bhakti Utama. 2007.

[8] Sugiyono. Metode Penelitian Pendidikan Pendekatan Kuantitatif, Kualitatif, dan R \& D. Bandung : Alfabeta. 2009.

[9] Sukmadinata, Nana Syaodih. Metode Penelitian Pendidikan. Bandung: Remaja Rosdakarya. 2008. 